\title{
Supercritical fluid extraction of $\beta$-carotene from ripe bitter melon pericarp
}

\author{
Avinash Singh Patel ${ }^{1}$, Abhijit Kar ${ }^{1 *}{ }^{*}$, Sukanta Dash ${ }^{2} \&$ Sanjaya K. Dash ${ }^{3}$
}

Study ascertained the recovery of $\beta$-carotene from enzyme-treated (enzyme load of $167 \mathrm{U} / \mathrm{g}$ ) pericarp of ripe bitter melon using supercritical fluid extraction (SFE) technique. Effect of different pressure (ranged from 150-450 bar), carbon dioxide $\left(\mathrm{CO}_{2}\right)$ flow rates (ranged from 15 to $55 \mathrm{ml} / \mathrm{min}$ ), temperatures (from 50 to $90^{\circ} \mathrm{C}$ ), and extraction periods (from 45-225 minutes) were observed on the extraction efficiency of $\beta$-carotene. Results showed that extraction pressure $\left(X_{1}\right)$ among extraction parameters had the most significant $(p<0.05)$ effect on extraction efficiency of the $\beta$-carotene followed by allowed extraction time $\left(\mathrm{X}_{4}\right), \mathrm{CO}_{2}$ flow rate $\left(\mathrm{X}_{2}\right)$ and the temperature of the extraction $\left(\mathrm{X}_{3}\right)$. The maximum yield of $90.12 \%$ of $\beta$-carotene from lyophilized enzymatic pretreated ripe bitter melon pericarp was achieved at the pressure of approx. $390 \mathrm{bar}$, flow rate of $35 \mathrm{~mL} / \mathrm{min}$, temperature at $70^{\circ} \mathrm{C}$ and extraction time of $190 \mathrm{~min}$, respectively. Based on the accelerated storage study the $70 \%$ retention shelf life of the $\beta$-carotene into extract was estimated up to 2.27 months at $10^{\circ} \mathrm{C}$ and up to 3.21 months at $5^{\circ} \mathrm{C}$.

Increasing the demand for natural colorants, concerning the derivation of researchers has rewarded the attention towards new biological resources instead of attention to chemical synthesis ${ }^{1-6}$. Several natural colors such anthocyanin, carotenoids, chlorophyll, betalains, iridoids, phycobiliproteins, etc. are extensively have been studied for their potential as a natural food colorant ${ }^{2,6-9}$. Moreover, these natural colorants have nutraceutical properties, which helps to fight against several diseases such as cancer, cardiac, inflammation, diabetes, neural problems, etc. ${ }^{1,6}$. Carotenoids are the yellowish-red pigments found in many plants, algae, and phototropic bacteria and have attracted vast research attention in the global market due to their potent antioxidant properties, ${ }^{8,10,11}$. Beta-carotene ( $\beta$-carotene) is one of the extensively used carotenoids as either additives or dietary supplements since years and helps in preventing several types of cancer including, lung, stomach and $\mathrm{skin}^{12-15}$. It is rehabilitated in the human body as a precursor of vitamin A (retinol) that is indispensable for appropriate function of the retina, epidermis and mucous membranes ${ }^{16}$ and providing other health benefits, including the possible prevention and treatment of cardiovascular disease $\mathrm{e}^{15,17}$.

At present the commercial production of the $\beta$-carotene is done by either chemical synthesis using $\beta$-ionone or from limited selective natural resources ${ }^{2,6,10,18}$. Among the natural sources of the beta-carotene viz., Dunaliella a green microalgae contains $2-3 \mathrm{~g}$ of beta-carotene per litre ${ }^{19}$, carrot contains $110 \mu \mathrm{g}$ per $100 \mathrm{~g}$ of fresh weight ${ }^{20}$ and Flavobacterium multivorum a bacteria contains $7.85 \mu \mathrm{g}$ per milliliter ${ }^{10}$ are the most commercial and widely used.

Bitter melon (Momordica charantia L.) is a climbing plant of Momordica genus mostly grown in Asian, African and Caribbean countries that have been used for various curative purposes ${ }^{21}$. The outer layer of the fruit is rough, known as pericarp, inner smooth tissue is an appendage or covering of seed called as aril. After ripening bitter melon, fruits turn to yellow due to their rich in carotenoids. Cultivation of ripe fruits at an industrial scale as well as farmer level is only for seed production however the waste and by-products generated during seed processing constitute a great source of $\beta$-carotene $(967 \mu \mathrm{g} / 100 \mathrm{~g}$ fresh weight), can be a potential for the commercialization for the beta-carotene production ${ }^{22,23}$.

Traditionally the extraction process of valuable compounds from agricultural produces is usually performed by using organic solvents; however, this chemical method may be toxic and has some pollution concern $\mathrm{s}^{24}$. One alternative to traditional extraction by organic solvents is to accomplish the extraction by $\mathrm{CO}_{2}$ based supercritical

${ }^{1}$ Division of Food Science and Postharvest Technology ICAR - Indian Agricultural Research Institute New Delhi, New Delhi, 110012, India. ${ }^{2}$ Division of Design and Experiments, ICAR - Indian Agricultural Statistics Research Institute, New Delhi, 110012, India. ${ }^{3}$ Division of Agricultural Processing \& Food Engineering, College of Agricultural Engineering \& Technology, Orissa University of Agricultural \& Technology, Bhubaneswar, 751003, India. *email: abhijit8366@gmail.com 
fluid extraction (SFE) method, which is used to extract numerous bioactive compounds due to its inflammable, protective solvent in nature that responsible for an anaerobic extraction results better stability than the organic solvent extraction ${ }^{25,26}$. The application of SFE technique to recover the essential compounds is more effective than other techniques, especially considering environmental protection. Moreover, eliminate the process of after separation from extracts resulting extensively pure ${ }^{27}$. $\beta$-Carotene extraction with SFE from tray dried carrots is an excellent technique suitable to replace the use of harmful organic solvents and satisfy the increasing demand for biological solvent-free $\beta$-carotene ${ }^{20}$. The extraction efficiency of targeted compounds depends upon the applied extraction parameters such as extraction pressure and temperature that both are significant SFE equipped constraint. In both indispensable characteristics of supercritical fluid, other factors such as the interaction between targeted compounds and ecological aspects are also important to extraction efficiency ${ }^{28}$. Due to these multi-faceted relations, a solitary condition of SFE cannot give sufficient information. To defeat this complexity, response surface methodology (RSM) a statistical investigational design has frequently been implemented to assist seems to be the optimum process factors ${ }^{29,30}$. Except for instrumental parameter, other factors such as enzymatic digestion, heat treatment, particle size, moisture content matrices play a key role in the extraction efficiency of targeted compounds ${ }^{31,32}$. These pretreatments may humiliate the complex structure of matrixes with targeted compounds and make it easily available and improve the content also by conversion process ${ }^{33,34}$. Since the call wall of plants is composed of main polysaccharides (cellulose, hemicelluloses) and heteropolysaccharide (pectin), most of the bioactive compounds are contained in these saccharides and bind to gather tightly. Enzymes mainly cellulase, pectinase, protease, and $\alpha$-amylase are used to make extraction efficiency of these compounds ${ }^{11,34}$.

Enzymatically pretreated and solvent added SFE of bioactive compounds were performed by many researchers ${ }^{34,35}$. SFE of $\beta$-carotene from different bio-resources were also studied ${ }^{20,36}$. However, very little or no reports are available on SFE of $\beta$-carotene from the ripe bitter melon pericarp. Hence, an attempt was made to investigate systematically the effects of SFE parameters on the percent yields of $\beta$-carotene from pretreated followed by lyophilized pericarp of ripe bitter melon.

In particular, interest lies in determining the effect of different SFE parameters on the extraction efficiency of beta-carotene from ripe bitter melon pericarp. A response surface methodology (RSM) tool is applied to optimize best set of combination of pressure, temperature, time and flow rate. Extracted beta-carotene is quantified using supercritical fluid chromatography (SFC) technique.

\section{Materials and Methods}

Materials. Ripe bitter melon was procured from the orchard of Indian Agricultural Research Institute, New Delhi. Chemicals and reagents in this experiment were purchased from Merck, KGaA-64271, Darmstadt, Germany. $\beta$-Carotene standard was purchased from Sigma-Aldrich (Chemie GmbH, Taufkirchen, Germany). Pectinase (456 U/g, Aspergillus sp.) was purchased from Sigma-Aldrich (Japan) and deep tube liquid $\mathrm{CO}_{2}$ (99.98\%) from Amit labs, New Delhi, India.

Sample preparation. Ripe bitter melon was washed in tap water to remove dust and foreign materials. The top and bottom portion of washed fruit were removed, then the whole fruit was cut one-sided lengthwise with help of knife. The aril with the seed of fruits was removed manually and collected pericarp was kept at $-20^{\circ} \mathrm{C}$ temperature.

Enzymatic digestion of pericarp. For the enzymatic pretreatment of the ripe bitter melon pericarp a method described by Ranveer et al. ${ }^{35}$ was used. A working enzyme solution of $167 \mathrm{U} / \mathrm{g}$ was prepared by diluting the stock enzyme solution into citrate buffer $(\mathrm{pH} 5.0)^{35}$. Reaction mixture was prepared in the ratio of 3:1 (enzymatic citrate buffer solution: pericarp). The reaction mixture was continuously stirred at $25^{\circ} \mathrm{C}$ for 4 hours. This mixture was filtered through Whatman No. 42 , and the residue was kept in a deep freezer $\left(-80^{\circ} \mathrm{Ce}\right)$ for 6 hours. The pericarp was lyophilized by Labconco lyophilizer (Kansas, USA) at the temperature of $-55^{\circ} \mathrm{C}$ with a vacuum of 0.1 mbar for 72 hours. The lyophilizing jars were wrapped with aluminum foil ( $11 \mu \mathrm{m}$ thickness) to avoid degradation.

Supercritical fluid extraction (SFE) of $\beta$-carotene. Before feeding the sample in 1 litre steel vessel of SFE, the lyophilized pericarp was powdered and sieved with standard 35 BSS mesh ( $500 \mu \mathrm{m}$ pore size). Extraction of $\beta$-carotene from powdered pericarp matrices was carried out at each of the experimental combinations through an automated SFE system (Model 7100, Thar Technologies Inc., USA). For each extraction run, the extraction vessel was loaded with $50 \mathrm{~g}$ of powdered pericarp matrix. Ethanol $(5 \%, \mathrm{w} / \mathrm{w})$ was used as a co-solvent to enhance the extraction yield ${ }^{30}$. SFE parameters during the study were controlled by software (SuperChrom SFC Suite v5.9, Thar Technologies Inc., USA). The systematic representation of the SFE system for extraction of $\beta$-carotene from powdered matrix shown in Fig. 1, which comprises two high-speed pumps, one is $\mathrm{CO}_{2}$ pump $(280 \mathrm{~mL} / \mathrm{min})$ and another is modifier pump $(150 \mathrm{~mL} / \mathrm{min})$. The extracted $\beta$-carotene at the end of each experiment was collected, vacuum concentrated and stored at $-20^{\circ} \mathrm{C}$ until quantitative analysis.

Analysis of total $\beta$-carotene (TBC). The extracted $\beta$-carotene was characterized quantitatively using supercritical fluid chromatography based ultra-performance conversance chromatography (Acquity UPC ${ }^{2}$ system, Waters Technologies, USA) equipped with a reverse-phase analytical polymeric High Strength Silica C18 (HSS C18 SB), $3 \times 100 \mathrm{~mm}$ with particle size $1.8 \mu \mathrm{m}$, as reported by Runco et al. ${ }^{37}$. Empower ${ }^{3}$ software was used to operate the system during the quantitative analysis of samples. 


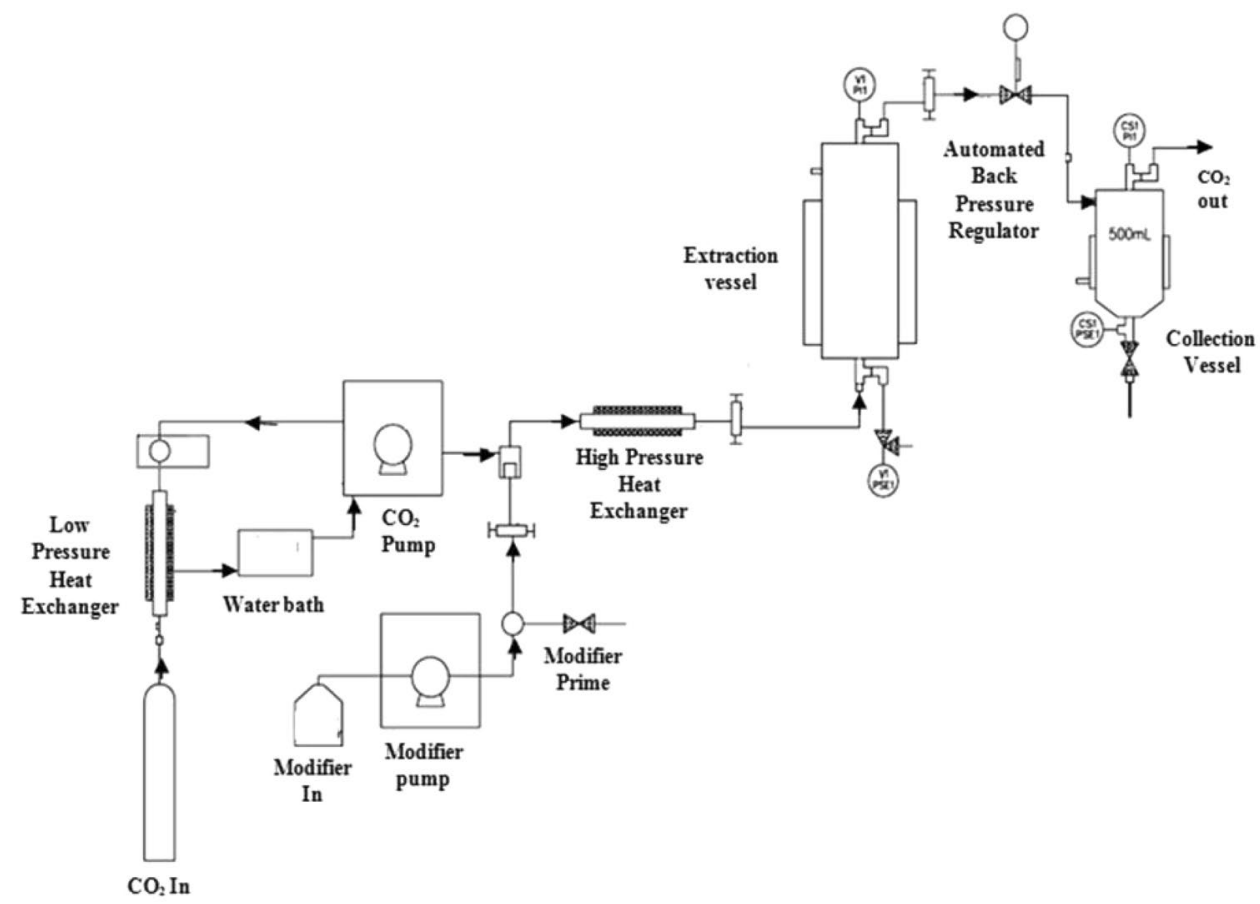

Figure 1. SFE process flowchart used in the extraction of $\beta$-carotene from the ripe bitter melon pericarp.

\begin{tabular}{|l|l|l|l|l|l|l|}
\hline \multirow{2}{*}{ Independent variables } & \multirow{3}{*}{ Symbols } & \multicolumn{6}{|c|}{ Coded variable levels } \\
\cline { 3 - 8 } & $\mathbf{- 2}$ & $\mathbf{- 1}$ & $\mathbf{0}$ & $\mathbf{1}$ & $\mathbf{2}$ \\
\hline Pressure $(\mathrm{bar})$ & $\mathrm{X}_{1}$ & 150 & 225 & 300 & 375 & 450 \\
\hline Flow rate $(\mathrm{mL} / \mathrm{min})$ & $\mathrm{X}_{2}$ & 15 & 25 & 35 & 45 & 55 \\
\hline Temperature $\left({ }^{\circ} \mathrm{C}\right)$ & $\mathrm{X}_{3}$ & 50 & 60 & 70 & 80 & 90 \\
\hline Time $(\min )$ & $\mathrm{X}_{4}$ & 45 & 90 & 135 & 180 & 225 \\
\hline
\end{tabular}

Table 1. Central composite rotatable design (CCRD) showing independent variables, their levels and responses.

Experimental layout. For optimization of the extraction parameters, the independent variables were coded as $\mathrm{X}_{1}$ (pressure), $\mathrm{X}_{2}$ (flow rate), $\mathrm{X}_{3}$ (temperature), and $\mathrm{X}_{4}$ (time) for maximum recovery of $\beta$-carotene using supercritical $\mathrm{CO}_{2}$ based SFE technique from ripe bitter melon pericarp matrices (Table 1). The whole experiment was designed to use the central composite design (CCD) of response surface methodology (RSM) resulted in thirty experiments and each was conducted for the optimization studies (Table 2). Data pertaining to five independent and one response variable were analysed to get a multiple regression equation:

$$
\begin{aligned}
Y= & b_{0}+b_{i} X_{i}+b_{j} X_{j}+b_{k} X_{k}+b_{l} X_{l}+b_{i j} X_{i j}+b_{i k} X_{i k}+b_{i l} X_{i l}+b_{j k} X_{j k}+b_{j l} X_{j l} \\
& +b_{k l} X_{k l}+b_{i i} X_{i}^{2}+b_{j j} X_{j}^{2}+b_{k k} X_{k}^{2}+b_{l l} X_{l}^{2}
\end{aligned}
$$

where $Y$ refers to the measured predicted $\%$ yield, $b_{0}$ is the intercept; $b_{i}, b_{j}$, and $b_{k}$ and $b_{1}$ are the linear terms; $b_{i j}$, $b_{i k}, b_{i l}, b_{j k}, b_{j l}$ and $b_{k l}$ are interaction coefficients and $b_{i i}, b_{j j}, b_{k k}$ and $b_{1 l}$ are quadratic terms, respectively.

Kinetics of accelerated storage study. The shelf-life prediction of foodstuff is based on environmental circumstance viz., temperature, humidity, microbes, etc., and its reaction kinetics. Under these environmental circumstances, the temperature is decisive to influence the storage kinetics. At optimum condition storage kinetics of SFE extract was conducted as are in the model suggested by Dien et al..$^{38}$. The extract was stored in transparent and amber-colored $30 \mathrm{~mL}$ airtight vial at $45^{\circ} \mathrm{C}$ and $55^{\circ} \mathrm{C}$ in incubator until it degraded up to $80 \%$. The frequency of analytical testing is the next important decision. The higher the storage temperature, the more frequent should be the testing.

\section{Results and Discussion}

During SFE, the moisture content of lyophilized pericarp powder was $6.45 \%$ (d.b.). The quantitative analysis of $\beta$-carotene content was studied by supercritical $\mathrm{CO}_{2}$ based $\mathrm{UPC}^{2}$ system using the standard calibration curve of $0,25,50,75,100,125$ and $150 \mathrm{ppm}$ (Fig. 2). Initially, $\beta$-carotene in ripe fresh pericarp was $7.63 \mathrm{mg} / 100 \mathrm{~g}$, however, enzymatic digestion increased it up to $21.05 \%(9.72 \mathrm{mg} / 100 \mathrm{~g})$ and $85.54 \mathrm{mg} / 100 \mathrm{~g}$ in digested dried powder. Enzymatic treatment improved the $\beta$-carotene content due to degradation of their interfacial tension, 


\begin{tabular}{|c|c|c|c|c|c|c|}
\hline \multirow[b]{2}{*}{ Run } & \multicolumn{4}{|c|}{ Independent variables levels (coded) } & \multicolumn{2}{|l|}{ Yield (\%) } \\
\hline & $\mathrm{X}_{1}$ & $\mathrm{X}_{2}$ & $\mathbf{X}_{3}$ & $\mathbf{X}_{4}$ & Experimental & Predicted \\
\hline 1 & -1 & -1 & -1 & 2 & 30.13 & 33.51 \\
\hline 2 & -1 & 1 & -1 & 1 & 45.44 & 42.50 \\
\hline 3 & 1 & -1 & -1 & 1 & 76.12 & 75.67 \\
\hline 4 & -1 & -1 & 1 & 1 & 48.84 & 43.14 \\
\hline 5 & -1 & -2 & 1 & -1 & 35.46 & 36.02 \\
\hline 6 & 1 & -1 & 1 & 1 & 51.60 & 54.63 \\
\hline 7 & 1 & 1 & -1 & -1 & 45.33 & 51.13 \\
\hline 8 & 1 & 1 & 1 & 1 & \begin{tabular}{|l|l|}
84.77 \\
\end{tabular} & \begin{tabular}{|l|l|}
81.51 \\
\end{tabular} \\
\hline 9 & 0 & 0 & 0 & 0 & \begin{tabular}{|l|l|}
76.51 \\
\end{tabular} & 76.53 \\
\hline 10 & 0 & 0 & 0 & 0 & \begin{tabular}{|l|l|}
78.48 \\
\end{tabular} & 76.53 \\
\hline 11 & 0 & 0 & 0 & 0 & 77.53 & 76.53 \\
\hline 12 & 0 & 0 & 0 & 0 & \begin{tabular}{|l|l|}
75.69 \\
\end{tabular} & 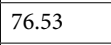 \\
\hline 13 & 0 & 0 & 0 & 0 & \begin{tabular}{|l}
74.91 \\
\end{tabular} & 76.53 \\
\hline 14 & 0 & 0 & 0 & 0 & \begin{tabular}{|l|l|}
76.12 \\
\end{tabular} & 76.53 \\
\hline 15 & -1 & -1 & -1 & 1 & \begin{tabular}{|l|l|}
43.64 \\
\end{tabular} & 42.21 \\
\hline 16 & -1 & 1 & -1 & -1 & 31.00 & 27.62 \\
\hline 17 & 1 & -1 & -1 & -1 & 50.11 & 52.90 \\
\hline 18 & -1 & -1 & 1 & -1 & 37.43 & 38.33 \\
\hline 19 & 1 & 1 & -1 & 1 & \begin{tabular}{|l|l|}
81.29 \\
\end{tabular} & \begin{tabular}{|l|l}
80.08 \\
\end{tabular} \\
\hline 20 & -1 & -1 & 1 & 1 & 50.11 & \begin{tabular}{|l|l}
47.01 \\
\end{tabular} \\
\hline 21 & 1 & -1 & 1 & 1 & 70.44 & 73.51 \\
\hline 22 & 1 & 1 & 1 & -1 & 55.34 & 56.45 \\
\hline 23 & 0 & 0 & 2 & 0 & 68.26 & \begin{tabular}{|l|l}
69.81 \\
\end{tabular} \\
\hline 24 & 0 & 0 & -2 & 0 & 64.96 & 63.56 \\
\hline 25 & 2 & 0 & 0 & 0 & \begin{tabular}{|l|l|}
80.02 \\
\end{tabular} & \begin{tabular}{|l|l|}
74.43 \\
\end{tabular} \\
\hline 26 & -2 & 0 & 0 & 0 & \begin{tabular}{|l|}
14.81 \\
\end{tabular} & 20.54 \\
\hline 27 & 0 & 2 & 0 & 0 & \begin{tabular}{|l}
37.79 \\
\end{tabular} & \begin{tabular}{|l|l}
40.87 \\
\end{tabular} \\
\hline 28 & 0 & -2 & 0 & 0 & \begin{tabular}{|l|l}
41.71 \\
\end{tabular} & \begin{tabular}{|l}
38.77 \\
\end{tabular} \\
\hline 29 & 0 & 0 & 0 & -2 & \begin{tabular}{|l|l}
45.41 \\
\end{tabular} & \begin{tabular}{|l}
38.19 \\
\end{tabular} \\
\hline 30 & 0 & 0 & 0 & 2 & 64.57 & 71.95 \\
\hline
\end{tabular}

Table 2. Central composite arrangement for independent variables.
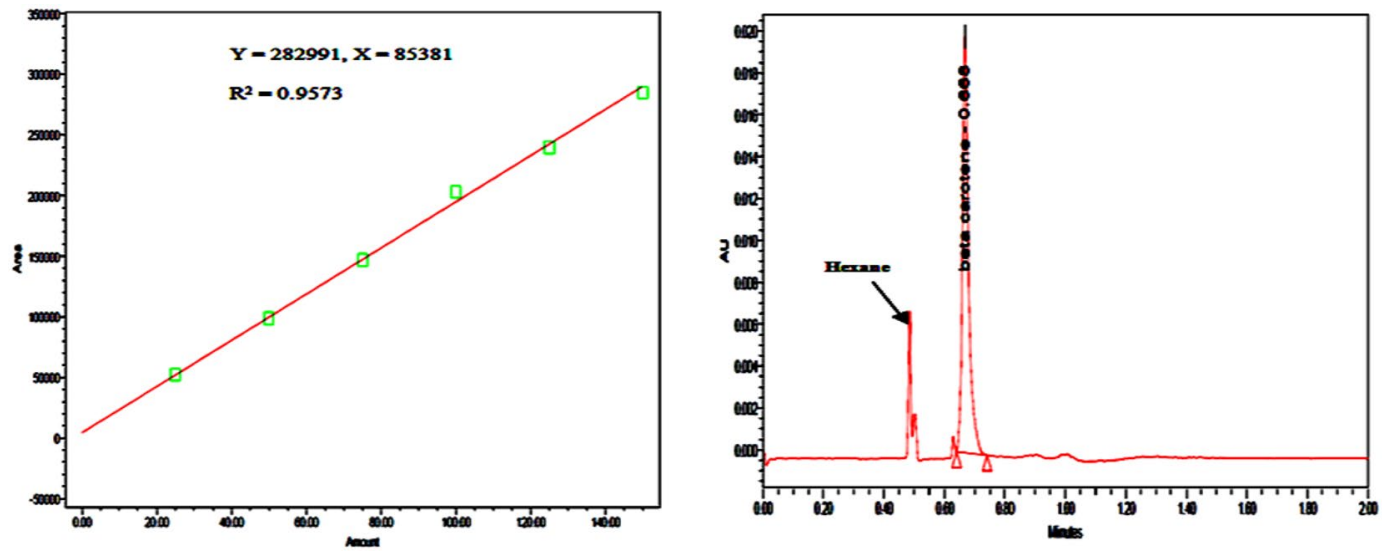

Figure 2. Supercritical fluid chromatography based $\mathrm{UPC}^{2}$ calibration curve (A) used in quantification of $\beta$-carotene extracted at the optimized condition and its chromatogram (B).

which increases its availability ${ }^{11,34}$. The reported results were in agreement with Lenucci et al. ${ }^{34}$ for tomato processing waste in which enzymatic treatment increased lycopene recovery up to $\sim 150 \%$. Vuong and King ${ }^{39}$ also reported the similar content of $\beta$-carotene in fresh Momordica genus ripe fruit (gac fruit) was 8.3 to $76.9 \mathrm{mg} / 100 \mathrm{~g}$. However, Tran et al. ${ }^{40}$ reported 37.9.mg/100 g in gac powder. 


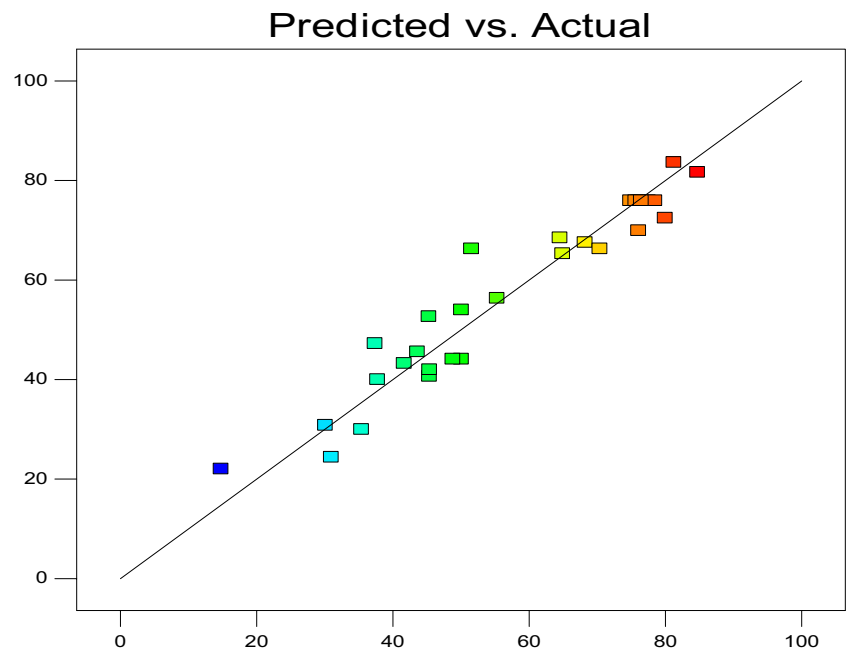

Figure 3. A plot of predicted and experimental value for the $\%$ yield of $\beta$-carotene extracted from ripe bitter melon pericarp using SFE technique.

\begin{tabular}{|l|l|l|l|l|}
\hline \multirow{2}{*}{ Regression } & \multicolumn{4}{|l|}{ Yield } \\
\cline { 2 - 5 } & DF & Sum of Squares & F-Value & Pr $>$ F \\
\hline Linear & 4 & 6132.400179 & 65.36 & $<0.0001$ \\
\hline Quadratic & 4 & 3613.201070 & 38.51 & $<0.0001$ \\
\hline Cross product & 6 & 290.457584 & 2.06 & 0.1195 \\
\hline Total Model & 14 & 10036 & 30.56 & $<0.0001$ \\
\hline Lack of Fit & 10 & 343.518284 & 20.66 & 0.0019 \\
\hline Pure Error & 5 & 8.315508 & - & - \\
\hline Total Error & 15 & 351.833792 & - & - \\
\hline
\end{tabular}

Table 3. Analysis of variance of (ANOVA) independent variables for the extraction of $\beta$-carotene from the ripe bitter melon pericarp. Note: R-Squares 0.9661, Degree of freedom (DF).

Extraction optimization. The data pertaining to the independent and response variables were analysed to get a regression equation with linear, square and interaction coefficients as follows:

$$
\begin{aligned}
Y= & -360.262743+0.837487 X_{1}+4.973891 X_{2}+3.890651 X_{3}+0.621753 X_{4} \\
& +0.001374 X_{1} X_{2}-0.001029 X_{1} X_{3}+0.001042 X_{1} X_{4}+0.008958 X_{2} X_{3} \\
& +0.003432 X_{2} X_{4}-0.002163 X_{3} X_{4}-0.001291 X_{1}^{2}-0.09177 X_{2}^{2} \\
& -0.024613 X_{3}^{2}-0.002650 X_{4}^{2}
\end{aligned}
$$

The predicted values of $\beta$-carotene content were calculated using the regression model and compared with experimental values. The value for the coefficient of determination $\left(\mathrm{R}^{2}\right)$ was 0.966 which indicates the adequacy of the applied model. The statistical analysis of data revealed that linear, quadratic and model were significant (Table 3). The ANOVA also showed that there was a non-significant $(p>0.0019)$ lack of fit which further validates the model. The scattered plot between the experimental values and difference between the experimental and predicted values did not show a pattern that further indicated the adequacy of the model (Fig. 3). The levels of independent variables for optimal extraction conditions of $\beta$-carotene content were determined using response surface graphs plotted between each independent variable (Table 3). Variation in extraction pressure $\left(\mathrm{X}_{1}\right)$ showed the most significant effect results in an increase in $\beta$-carotene recovery. Maximum $\beta$-carotene content was obtained at 393.32 bar; however, further increase in pressure up to 450 bar showed negative effect in \% yield (Fig. 4A). Increase in pressure beyond a critical limit decreases the diffusion ability of supercritical $\mathrm{CO}_{2}$ mainly because of the enhanced compaction of the samples at higher pressure leading to chainaling of the supercritical $\mathrm{CO}_{2}$ around it rather than diffusing through it ${ }^{41,42}$. Kaur et al. ${ }^{20}$ reported similar trends for SFE of $\beta$-carotene from tray dried carrot. Results in case of flow rate $\left(\mathrm{X}_{2}\right)$ was observed as list significant change in $\beta$-carotene yield; however, at a fixed flow rate of $35 \mathrm{~mL} / \mathrm{min}$ was found to be the best. The increase in flow rate beyond $35 \mathrm{~mL} / \mathrm{min}$ reduces yield significantly. This may be either the enhanced rate of dissolution of solute into the solvent or solvent might have passed touching the sample rather than penetrating inside it, because of the reduced solute-solvent interaction and dwell time of the sample in the extraction vessel as described by Topal et al. ${ }^{43}$. Temperature is an important consideration in any extraction on SFE. As an expected increase in temperature up to about $70^{\circ} \mathrm{C}$ 


\section{Response Surfaces}
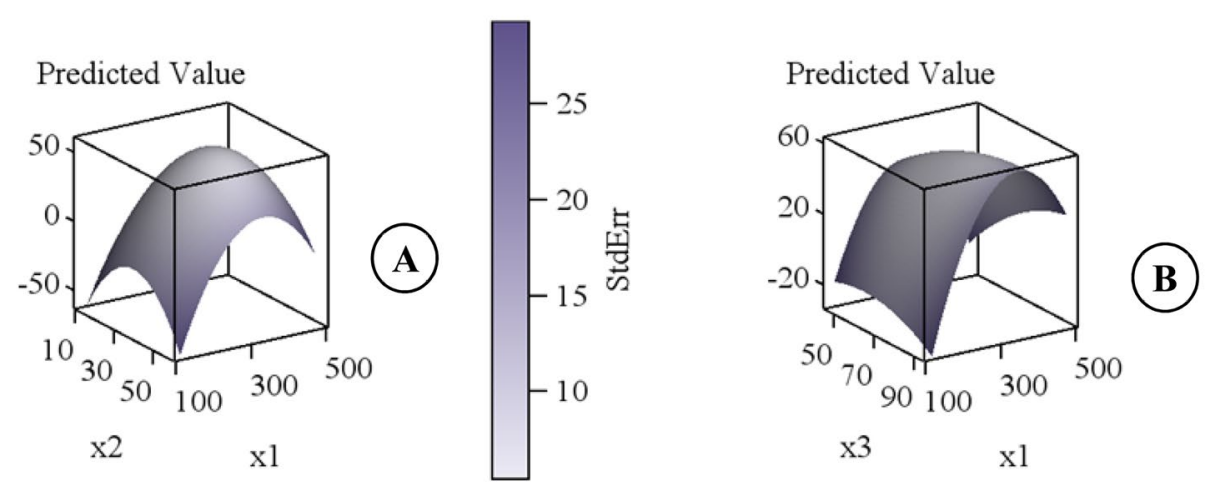

点
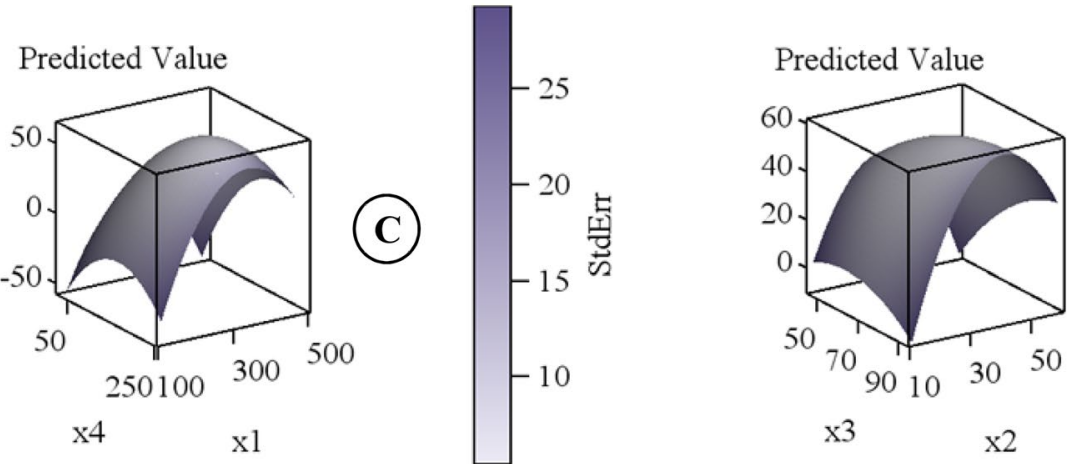

(D)
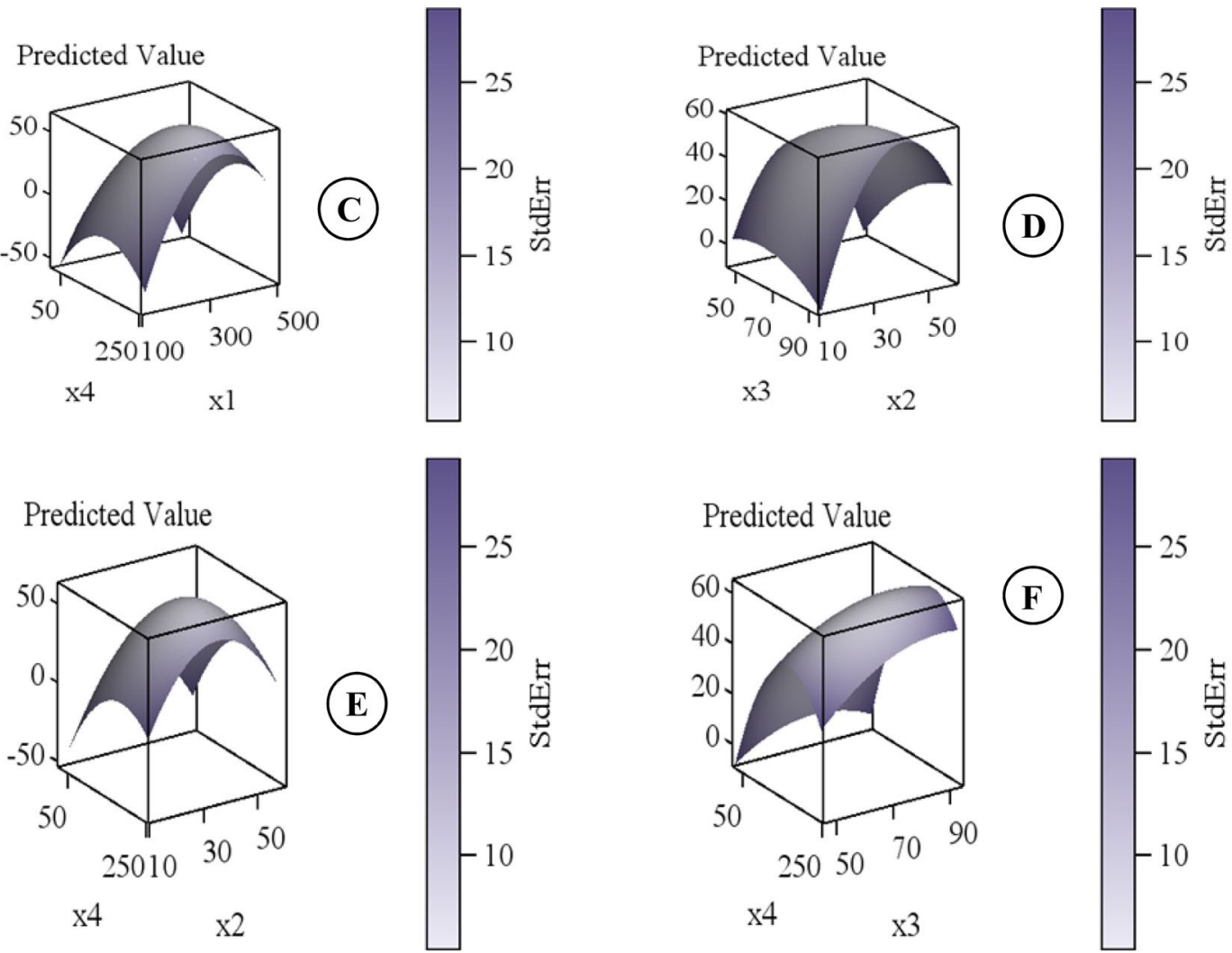

Figure 4. Response surface plot showing effects of independent variables on \% yield (A-F) from ripe bitter melon pericarp while the remaining were kept at the central point (pressure: $\mathrm{X}_{1}-300$ bar; flow rate: $\mathrm{X}_{2}-35 \mathrm{~mL}$ / min; temperature: $\mathrm{X}_{3}-70^{\circ} \mathrm{C}$; and time: $\mathrm{X}_{4}-135 \mathrm{~min}$ ).

\begin{tabular}{|l|c|l|l|l|}
\hline \multirow{2}{*}{ Factor } & \multicolumn{2}{|l|}{ Critical Value } & \multicolumn{2}{l|}{ Coding Coefficients } \\
\cline { 2 - 5 } & Coded & Un-coded & Subtracted off & Divided by \\
\hline $\mathrm{X}_{1}$ & 0.62 & 393.32 & 300.00 & 150.00 \\
\hline $\mathrm{X}_{2}$ & 0.099 & 36.98 & 35.00 & 20.00 \\
\hline $\mathrm{X}_{3}$ & -0.04 & 69.15 & 70.00 & 20.00 \\
\hline $\mathrm{X}_{4}$ & 0.62 & 190.36 & 135.00 & 90.00 \\
\hline
\end{tabular}

Table 4. Canonical analysis of response surface based on coded data for TBC and yield. Predicted value at the stationary point for $\%$ yield $=90.11$.

increases $\beta$-carotene yield at any given pressure since higher temperatures promote the solubility of solute and increase the \% yield by the high mass transfer of solute in the matrix ${ }^{44}$. However, the same reduces drastically with any further increase in temperature beyond $70^{\circ} \mathrm{C}$. This can be explained by the loss of balance between 


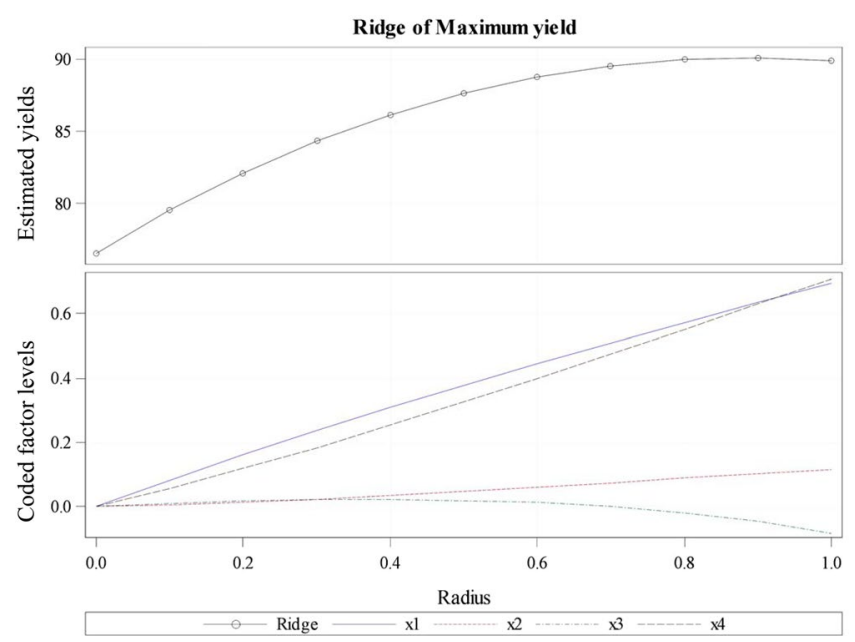

Figure 5. An estimated ridge of maximum response for variable \% yield.

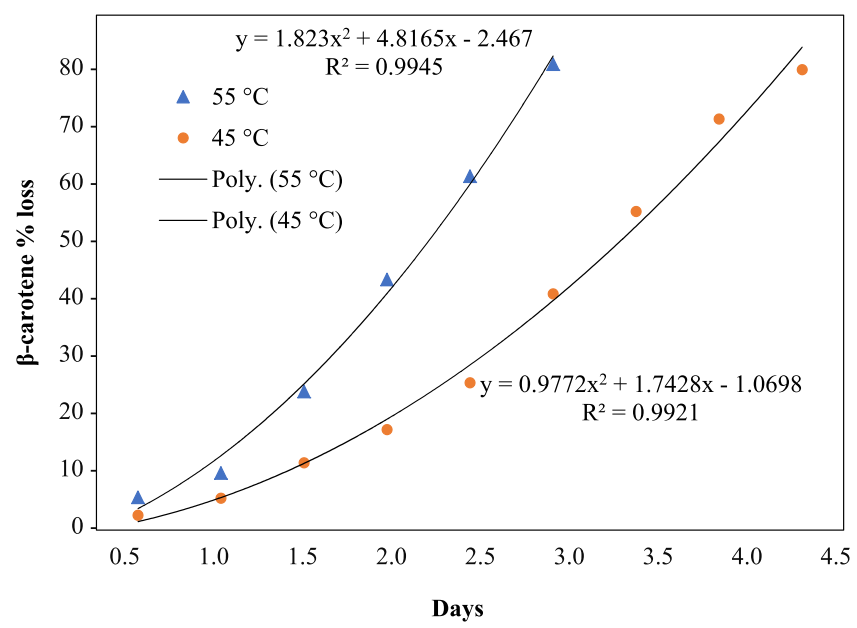

Figure 6. Effect of temperature $55^{\circ} \mathrm{C}(\mathrm{A})$ and $45^{\circ} \mathrm{C}(\mathbf{B})$ percentage loss and TBC extracted from ripe bitter melon pericarp at optimum condition.

the supercritical $\mathrm{CO}_{2}$ density and the solute vapor pressure. The effect of temperature at any given time period also remains the same up to a threshold value beyond which the extraction yields have significantly reduced (Fig. 4B). This could be due to the adverse effect of temperature leading to $\beta$-carotene degradation and isomerization as suggested by Gomez-Prieto et al..$^{45}$ and Nobre et al. ${ }^{46}$. Extraction time, in fact, decides the amount of supercritical $\mathrm{CO}_{2}$ available for the extraction process. In case the available supercritical $\mathrm{CO}_{2}$ is a limiting factor, the completeness of extraction is adversely affected ${ }^{47}$. However, the increase in time period beyond a point where the available supercritical $\mathrm{CO}_{2}$ suffices the completeness of extraction could lead to detrimental effect because of other controlling parameters like temperature. Pressure level as described earlier could play a significant role either in aiding extraction by solvent densification or limit it because of sample compaction ${ }^{45,47}$. Hence, an appropriate balance between the two factors is essential for maximization of $\beta$-carotene yields (Fig. $4 \mathrm{C}$ ). This is further strengthened by the surface plot between the temperature of extraction and the flow rate of supercritical $\mathrm{CO}_{2}$ (Fig. 4D). It can be clearly seen that increase in extraction time significantly enhances the $\beta$-carotene yields since it leads to enhance the time of the solvent with the solutes thereby enhancing the penetration and subsequent extraction of $\beta$-carotene from the sample matrix; however, increasing inflow rate of supercritical $\mathrm{CO}_{2}$ resulted in no significant effect (Fig. $4 \mathrm{E}$ ). The interface between extraction time and temperature as shown in Fig. $4 \mathrm{~F}$ was found to be significantly influenced by these independent variables. At initial extraction temperature increasing the time, resulting in an advantageous effect on $\beta$-carotene yield, however, a further increase in the temperature beyond $70^{\circ} \mathrm{C}$ lead to extensive degradation of thermo-sensible $\beta$-carotene resulted in the loss of yield ${ }^{41,47}$. Based on a statistical analysis of data using PROCRSREG of SAS, it was found that a maximum extraction efficiency of $90.12 \%$ of $\beta$-carotene could be achieved using $69.15^{\circ} \mathrm{C}$ temperature, 393.31 bar pressure, $36.98 \mathrm{~mL} / \mathrm{min}$ flow rate for $190.36 \mathrm{~min}$ (Table 4). 
Confirmatory studies. Additionally, three experimental runs were conducted at the optimum combination of independent variables to validate the same. The extraction yield obtained was $91.61 \%, 88.92 \%$ and $87.56 \%$ (mean value of $89.36 \pm 0.68 \%$ ) indicating good agreement with the results using statistical modeling. For justification of the above independent variables, the estimated ridge of maximum response for the dependent variable (\% yield) shown in Fig. 5, revealed that the maximum yield was $90.099 \%$ at stationary point X1 $=395.002$ bar, $\mathrm{X} 2=37.03 \mathrm{~mL} / \mathrm{min}, \mathrm{X} 3=69.03^{\circ} \mathrm{C}$ and $\mathrm{X} 4=191.66 \mathrm{~min}$.

Effect of storage temperature on storage stability. In our experiments, we recognized quite clearly that total carotene decrease day by days when preserving $\beta$-carotene at $55^{\circ} \mathrm{C}$ than $45^{\circ} \mathrm{C}$. Although all sample is kept in an incubator in airtight amber color vials, $\beta$-carotene owing to decomposition at high temperature, its bound energy goes from basic energy to excitation energy so molecule breakdown. At higher storage temperature the storage stability was 2.5 days with $90.48 \%$ loss than lower temperature $\left(45^{\circ} \mathrm{C}\right) 5$ days with $89.41 \%$ loss (Fig. 6). Calculating from the above figure using polynomial equations, in order to get carotene $30 \%$, it should keep within 3.09 days $\left(55^{\circ} \mathrm{C}\right)$ and 6.16 days $\left(45^{\circ} \mathrm{C}\right)$.

$$
Q_{10}=\frac{6.16}{3.09}=1.99
$$

where $\mathrm{Q}_{10}$ is increase in the rate of the reaction when the temperature is increased by $10^{\circ} \mathrm{C}$ during storage.

Storage duration at of $\beta$-carotene at $10^{\circ} \mathrm{C}$ (Eq. (4)) and $5^{\circ} \mathrm{C}$ (Eq. (5)) (carotene $30 \%$ reduction) will be:

$$
\begin{aligned}
& F_{2}=f_{1} \times Q_{10}^{\frac{\Delta}{10}}=3.09(199)^{\frac{55-10}{10}}=68.36 \text { days } \approx 2.27 \text { months } \\
& F_{2}=f_{1} \times Q_{10}^{\frac{\Delta}{10}}=3.09(199)^{\frac{55-5}{10}}=96.43 \text { days } \approx 3.21 \text { months }
\end{aligned}
$$

where $\mathrm{f}_{1}$ - time between tests at the higher temperature, $\mathrm{F}_{2}$ - storage life at the lower temperature, $\Delta$ - difference in degrees centigrade between the two.

Therefore, we can keep $\beta$-carotene within 2.27 months at $10^{\circ} \mathrm{C}$ or 3.21 months at $5^{\circ} \mathrm{C}$ to maintain $70 \%$ TBC carotene. Retention of extracted $\beta$-carotene from gac fruit (Momordica cochinchinensis Spreng) stored at the same storage temperature was also agreeable with this study ${ }^{38}$.

\section{Conclusion}

SFE of $\beta$-carotene from the ripe pericarp of Momordica genus has gained great attention in the current year. The study reviewed show that ripe bitter melon pericarp SFE- $\mathrm{CO}_{2}$ extracts are interesting, innovative, and high-quality products rich with $\beta$-carotene. Optimization of experimental parameters, such as pressure, $\mathrm{CO}_{2}$ flow rate, temperature and extraction period of enzymatically treated lyophilized ripe bitter melon pericarp matrix was done. The experimental values of $\beta$-carotene yield were varied from $14.81 \%$ to $84.77 \%$. The statistical model revealed the thirty experiment to optimize the best extraction condition of SFE. The second-order model developed for $\beta$-carotene yield exhibited non-significant lack of fit and a high value for the coefficient of determination (0.9661). The surface graph indicated that maximum $\beta$-carotene $\%$ yield was obtained by extracting ripe bitter melon pericarp at $69.15^{\circ} \mathrm{C}$ temperature, 393.31 bar pressure, $36.98 \mathrm{~mL} / \mathrm{min}$ flow rate for $190.36 \mathrm{~min}$. The expected storage stability of extracted $\beta$-carotene in the amber-colored vial to strictly restrict oxygen and light was 2.27 months at $10^{\circ} \mathrm{C}$ or 3.21 months at $5^{\circ} \mathrm{C}$ can maintain $70 \%$ of $\beta$-carotene.

Ethical approval. Informed consent: This article does not contain any studies with either animals or human participants performed by any of the authors.

Received: 3 October 2019; Accepted: 25 November 2019;

Published online: 17 December 2019

\section{References}

1. Delgado-Vargas, F. \& Paredes-Lopez, O. Natural colorants for food and nutraceutical uses. CRC press. pp. 344, (2002).

2. Aberoumand, A. A review article on edible pigments properties and sources as natural biocolorants in foodstuff and food industry. World J. Dairy Food Sci. 6(1), 71-78 (2011).

3. Ghosh, P., Pradhan, R. C., Mishra, S., Patel, A. S. \& Kar, A. Physicochemical and nutritional characterization of jamun (Syzygium cuminii). Cur. Res. Nutr. Food Sci. J. 5(1), 25-35 (2017).

4. Mishra, B. B., Patel, A. S. \& Kar, A. Storage Stability of Encapsulated Anthocyanin-Rich Extract from Black Carrot (Daucus carota ssp. Sativus) using different Coating Materials. Cur. Agric. Res. 7(1), 51-63, https://doi.org/10.12944/CARJ.7.1.07 (2019).

5. Murali, S., Kar, A. \& Patel, A. S. Storage stability of encapsulated black carrot powder prepared using spray and freeze-drying techniques. Cur. Agric. Res. 7(2), 261-267 (2019).

6. Rodriguez-Amaya, D. B. Natural food pigments and colorants. Bioact. Mol. Food 8, 867-901 (2019).

7. Dhakane, J. P., Kar, A., Patel, A. S. \& Khan, I. Effect of soy proteins and emulsification-evaporation process on physical stability of lycopene emulsions. Int. J. Chem. Studies 5(5), 1354-1358 (2017).

8. Patel, A. S., Kar, A. \& Khan, I. Process for development of $\beta$-carotene Nanocomposites with $\omega$-fatty acids. (VBRI press), https:// scholar.google.com/scholar? cluster=8793510290280437556\&hl=en\&oi=scholarr, Accessed on 08.15.2019 (2017).

9. Kar, A., Mahato, D. K., Patel, A. S. \& Bal, L. M. The Encapsulation Efficiency and Physicochemical Characteristics of Anthocyanin from Black Carrot (Daucus carota ssp. Sativus) as Affected by Encapsulating Materials. Cur. Agric. Res. 7(1), 26-36 (2019).

10. Bhosale, P. \& Bernstein, P. S. $\beta$-Carotene production by Flavobacterium multivorum in the presence of inorganic salts and urea. J. Ind. Microb. Biotechnol. 31(12), 565-571 (2004). 
11. Mai, H. C., Truong, V. \& Debaste, F. Optimization of enzyme-aided extraction of oil rich in carotenoids from gac fruit (Momordica cochinchinensis Spreng.). Food Technol. Biotechnol. 51(4), 488-499 (2013).

12. Omenn, G. S. Chemoprevention of lung cancer: the rise and demise of beta-carotene. Annu. Rev. Pub. Health 19(1), 73-99 (1998).

13. Ray, A. Cancer preventive role of selected dietary factors. Indian J. Cancer 42(1), 15-24 (2005).

14. Borek, C. Dietary Antioxidants and Human Cancer. J. Restorative Med. 6(1), 53-61 (2017).

15. Meléndez-Martínez, A. J. An Overview of Carotenoids, Apocarotenoids and Vitamin A in Agro-Food, Nutrition, Health and Disease. Mol. Nutri. Food Res. 1801045, https://doi.org/10.1002/mnfr.201801045 (2019)

16. Dawson, M. I. The importance of vitamin A in nutrition. Cur. Pharma Des. 6(3), 311-325 (2000).

17. Jha, P., Flather, M., Lonn, E., Farkouh, M. \& Yusuf, S. The Antioxidant Vitamins and Cardiovascular Disease: A Critical Review of Epidemiologic and Clinical Trial Data. Anal. Internal Med. 123(11), 860-872 (1995).

18. Ribeiro, B. D., Barreto, D. W. \& Coelho, M. A. Z. Technological aspects of $\beta$-carotene production. Food Bioprocess Technol. 4(5), 693-701 (2011)

19. Emeish, S. Production of natural $\beta$-carotene from Dunaliella living in the Dead Sea. Jordan J. Earth Environ. Sci. 4(2), 23-27 (2012).

20. Kaur, K., Shivhare, U. S., Basu, S. \& Raghavan, G. V. Kinetics of Extraction of $\beta$-Carotene from Tray Dried Carrots by Using Supercritical Fluid Extraction Technique. Food Nutr. Sci. 3(5), 591-595 (2012).

21. Lee-Huang, S. et al. Anti-HIV and anti-tumor activities of recombinant MAP30 from bitter melon. Gene 161(2), 151-156 (1995).

22. Rodriguez, D. B., Raymundo, L. C., Lee, T. C., Simpson, K. L. \& Chichester, C. O. Carotenoid pigment changes in ripening Momordica charantia fruits. Anal. Bot. 40(3), 615-624 (1976).

23. Kandlakunta, B., Rajendran, A. \& Thingnganing, L. Carotene content of some common (cereals, pulses, vegetables, spices and condiments) and unconventional sources of plant origin. Food Chem. 106(1), 85-89 (2008).

24. Shams, K. A. et al. Green technology: economically and environmentally innovative methods for extraction of medicinal \& aromatic plants (MAP) in Egypt. J. Chem. Pharm. Res 7(5), 1050-1074 (2015).

25. Lang, Q. \& Wai, C. M. Supercritical fluid extraction in herbal and natural product studies-a practical review. Talanta 53(4), 771-782 (2001)

26. Joana Gil-Chávez, G. et al. Technologies for extraction and production of bioactive compounds to be used as nutraceuticals and food ingredients: an overview. Compr. Rev. Food Sci. F. 12(1), 5-23 (2013).

27. Brunner, G. (2005). Supercritical fluids: technology and application to food processing. J. Food Eng. 124, 105-116 (2014).

28. Sharif, K. M. et al. Experimental design of supercritical fluid extraction-A review. J. Food Eng. 124, 105-116 (2014).

29. Patil, P. D. et al. Optimization of direct conversion of wet algae to biodiesel under supercritical methanol conditions. Bioresour. Technol. 102(1), 118-122 (2011).

30. Sanal, İ. S., Bayraktar, E., Mehmetoğlu, Ü. \& Calımlı, A. Determination of optimum conditions for SC-(CO2+ethanol) extraction of $\beta$-carotene from apricot pomace using response surface methodology. J. Supercrit. Fluids 34(3), 331-338 (2005).

31. Sowbhagya, H. B. \& Chitra, V. N. Enzyme-assisted extraction of flavorings and colorants from plant materials. Critic. Rev. Food Sci. Nutri. 50(2), 146-161 (2010).

32. Durante, M., Lenucci, M. \& Mita, G. Supercritical carbon dioxide extraction of carotenoids from pumpkin (Cucurbita spp.): a review. Int. J. Mol. Sci. 15(4), 6725-6740 (2014).

33. Dominguez, H., Nunez, M. J. \& Lema, J. M. Enzymatic pretreatment to enhance oil extraction from fruits and oilseeds: a review. Food Chem. 49(3), 271-286 (1994).

34. Lenucci, M. S. et al. Enzyme-aided extraction of lycopene from high-pigment tomato cultivars by supercritical carbon dioxide. Food Chem. 170, 193-202 (2015).

35. Ranveer, R. C., Patil, S. N. \& Sahoo, A. K. Effect of different parameters on enzyme-assisted extraction of lycopene from tomato processing waste. Food Bioprod. Process. 91(4), 370-375 (2013).

36. Singh, D., Barrow, C. J., Mathur, A. S., Tuli, D. K. \& Puri, M. Optimization of zeaxanthin and $\beta$-carotene extraction from Chlorella saccharophila isolated from New Zealand marine waters. Biocatal. Agric. Biotechnol. 4(2), 166-173 (2015).

37. Runco, J., Subbarao, L. \& Chen, R. Qualitative and Quantitative Analysis of $\beta$-carotene Using UPC2. APNT134719455, Water, Mississauga, ON (2013).

38. Dien, L. K. L., Minh, N. P. \& Dao, D. T. A. The changes of total carotenoid content of gac (Momordica cochinchinensis Spreng.) powder product in accelerated temperature to the appropriate temperature and shelf-life of product storage. Int. Res. J. Natur. Sci 2, $31-37$ (2014).

39. Vuong, L. T. \& King, J. C. A method for preserving gac fruit oil, a rich source of beta-carotene and essential fatty acids in North Vietnam. Food Nutr. Bull. 24, 372-373 (2003).

40. Tran, T. H., Nguyen, M. H., Zabaras, D. \& Vu, L. T. Process development of Gac powder by using different enzymes and drying techniques. J. Food Eng. 85(3), 359-365 (2008).

41. Rozzi, N. L., Singh, R. K., Vierling, R. A. \& Watkins, B. A. Supercritical fluid extraction of lycopene from tomato processing byproducts. J. Agric. Food Chem. 50(9), 2638-2643 (2002).

42. Reverchon, E. \& De Marco, I. Supercritical fluid extraction and fractionation of natural matter. J. Supercrit. Fluid. 38(2), 146-166 (2006).

43. Topal, U., Sasaki, M., Goto, M. \& Hayakawa, K. Extraction of lycopene from tomato skin with supercritical carbon dioxide: effect of operating conditions and solubility analysis. J. Agric. Food Chem. 54(15), 5604-5610 (2006).

44. Marsili, R. \& Callahan, D. Comparison of a liquid solvent extraction technique and supercritical fluid extraction for the determination of $\alpha$ - and $\beta$-carotene in vegetables. J. Chromatogr. Sci. 31(10), 422-428 (1993).

45. Gómez-Prieto, M. S., Caja, M. M., Herraiz, M. \& Santa-María, G. Supercritical fluid extraction of all-trans-lycopene from tomato. J. Agric. Food Chem. 51(1), 3-7 (2003).

46. Nobre, B. P., Palavra, A. F., Pessoa, F. L. \& Mendes, R. L. Supercritical $\mathrm{CO}_{2}$ extraction of trans-lycopene from Portuguese tomato industrial waste. Food Chem. 116(3), 680-685 (2009).

47. Abbas, K. A., Mohamed, A., Abdulamir, A. S. \& Abas, H. A. A review on supercritical fluid extraction as new analytical method. Am. J. Biochem. Biotechnol. 4(4), 345-353 (2008).

\section{Acknowledgements}

Indian Council of Agricultural Research (ICAR), New Delhi, Govt. of India, is acknowledged for rendering the financial support under the program "National Fund for Basic, Strategic and Frontier Application Research in Agriculture (NFBSFARA)" to carry out the present work.

\section{Author contributions}

Avinash Singh Patel initiated the study, executed the experiments, collected, prepared the figures and wrote the manuscript. Abhijit Kar designed the experiments, supervised the study and reviewed the manuscript. Sukanta Das analyzed the data, Sanjaya K Dash reviewed the manuscript and contributed in data interpretation. All authors have read and approved the final manuscript. 


\section{Competing interests}

The authors declare no competing interests.

\section{Additional information}

Correspondence and requests for materials should be addressed to A.K.

Reprints and permissions information is available at www.nature.com/reprints.

Publisher's note Springer Nature remains neutral with regard to jurisdictional claims in published maps and institutional affiliations.

(c) (i) Open Access This article is licensed under a Creative Commons Attribution 4.0 International License, which permits use, sharing, adaptation, distribution and reproduction in any medium or format, as long as you give appropriate credit to the original author(s) and the source, provide a link to the Creative Commons license, and indicate if changes were made. The images or other third party material in this article are included in the article's Creative Commons license, unless indicated otherwise in a credit line to the material. If material is not included in the article's Creative Commons license and your intended use is not permitted by statutory regulation or exceeds the permitted use, you will need to obtain permission directly from the copyright holder. To view a copy of this license, visit http://creativecommons.org/licenses/by/4.0/.

(c) The Author(s) 2019 